\title{
|DIREITOS FUNDAMENTAIS E O DEVER DE PROTEÇÃO: UMA ANÁLISE PAUTADA NO SISTEMA CONSTITUCIONAL E NA DECISÃO DO CASO DAMIÃO XIMENES LOPES VS. BRASIL NA CORTE INTERAMERICANA DE DIREITOS HUMANOS
}

\author{
FUNDAMENTAL RIGHTS AND "STATE PROTECTION DUTY”: AN ANALYSIS CONSIDERING THE \\ CONSTITUTIONAL SYSTEM AND THE DAMIÃO XIMENES LOPES VS. BRAZIL CASE AT THE \\ INTERAMERICAN COURT OF HUMAN RIGHTS
}

Mônia Clarissa Hennig Leal ${ }^{1}$ Cleize Carnelinda Kohls ${ }^{2}$

Resumo: Neste trabalho apresenta-se uma reflexão sobre os direitos fundamentais e o dever de proteção, abordando o caso de Damião Ximenes Lopes, bem como as contribuições da respectiva decisão da Corte Interamericana de Direitos Humanos para a proteção e concretização de direitos fundamentais no Brasil. O estudo é baseado em uma pesquisa bibliográfica e legislativa, utiliza-se de estudo de caso, com método dedutivo e procedimento estruturalista. A análise proposta busca respostas para a seguinte pergunta: como e em que medida o dever de proteção é abordado pela Corte Interamericana de Direitos Humanos da decisão estudada, com vistas à proteção e efetivação de direitos humanos e fundamentais? Objetivando responder a tal questionamento, a investigação parte dos aspectos introdutórios e evolutivos do tema, analisando os direitos fundamentais, especialmente na Constituição de 1988. Após, analisa o dever de proteção, e, notadamente, a dimensão objetiva dos direitos fundamentais. Por fim, aborda a decisão do caso Damião Ximenes Lopes na Corte Interamericana de Direitos Humanos, pontuando as contribuições que dita decisão traz ao ordenamento jurídico, notadamente como marco importante para a proteção de direitos e implementação de políticas públicas. Assim, o estudo apresenta subsídios teóricos que podem contribuir para a melhor compreensão do tema e verifica a sua aplicação em caso concreto.

Palavras-chave: Direitos fundamentais. Dever de proteção estatal. Corte Interamericana de Direitos Humanos. Caso Ximenes Lopes v. Brasil.
Abstract: This paper presents a reflection on fundamental rights and the duty of state protection, addressing the case of Damião Ximenes Lopes, as well as the contributions of the respective decision of the Inter-American Court of Human Rights for the protection and concretization of fundamental rights in Brazil. The study is based on a bibliographical and legislative research and uses a case study, with deductive method and structuralist procedure. The proposed analysis seeks answers to the following question: how and to what extent is the duty of protection addressed in the protection and enforcement of fundamental rights? In order to answer such questioning, the investigation starts with the introductory and evolutionary aspects of the theme, analyzing fundamental rights, especially in the 1988 Constitution. After, analyzing the duty of protection, and, in particular, the objective dimension of fundamental rights. Finally, it addresses the decision of the Damião Ximenes Lopes case in the Inter-American Court of Human Rights, punctuating the contributions that this decision brings to the legal order, notably as an important landmark for the protection of rights and the implementation of public policies. Thus, the study presents theoretical contributions that can contribute to a better understanding of the theme, and verifies its application in a concrete case.

Keywords: Fundamental rights. State protection duty. Inter-American Court of Human Rights. Case Ximenes Lopes v. Brasil.

Pós-Doutora na Ruprecht-Karls Universität Heidelberg (Alemanha); Doutora em Direito pela Universidade do Vale do Rio dos Sinos (com pesquisas realizadas junto à Ruprecht-Karls Universität Heidelberg, na Alemanha); Professora no Programa de Pós-Graduação em Direito - Mestrado e Doutorado - da Universidade de Santa Cruz do Sul; moniah@unisc.br Mestre em Direito, na linha de pesquisa de Constitucionalismo Contemporâneo, pela Universidade de Santa Cruz do Sul; Graduada em Direito pela Faculdade Dom Alberto; Professora na Universidade de Santa Cruz do Sul; Avenida Independência, 2293, Universitário, 96815-900, Santa Cruz do Sul, Rio Grande do Sul, Brasil; cleizek@hotmail.com 


\section{Introdução}

Muitas mudanças ocorreram no decorrer dos tempos na elaboração, aplicação e interpretação do direito. Essas alterações afetaram o relacionamento do homem com o Estado e também a sua relação com os outros indivíduos. O direito não é mais um simples instrumento para alcançar um determinado fim, mas é o próprio fim, ou seja, presta-se para servir às pessoas e, sobretudo, para garantir-lhes a dignidade e a efetivação dos direitos fundamentais.

Nesse sentido, os Poderes (Legislativo, Executivo e Judiciário) cumprem uma importante tarefa na realização dos direitos humanos e fundamentais, cada um dentro de suas competências e atribuições. Não obstante isso, sabe-se que esse papel nem sempre é bem desempenhado, o que enseja a omissão ou sonegação de proteção de ditos direitos.

E isso fica ainda mais evidente quando analisado em um caso concreto, como o de Damião Ximenes Lopes, já que se trata de caso que levou à condenação do Brasil pela Corte Interamericana de Direitos Humanos, por violação de direitos da vítima, como integridade física, vida e saúde de pessoa com deficiência mental internada em casa de repouso, bem como por violação de direitos de seus familiares, de garantias judiciais e de proteção judicial, quando da análise do referido caso pelo justiça brasileira.

Assim, a visão dos direitos fundamentais sob a perspectiva da dimensão objetiva também faz eclodir o debate sobre o dever de proteção e de realização de tais direitos, sendo que esse assunto permeia a necessidade de entender o que compreende essa noção, bem como quais as consequências que tem na análise de um caso concreto. Em razão disso, o tema é complexo e carecedor de pesquisas e discussões.

E é por isso que neste estudo se busca encontrar elementos que possam servir para encontrar respostas para o seguinte problema: como e em que medida o dever de proteção é abordado pela Corte Interamericana de Direitos Humanos da decisão estudada, com vistas à proteção e efetivação de direitos humanos e fundamentais?

Para tanto, o presente estudo é baseado em uma pesquisa bibliográfica e legislativa, com estudo de caso (decisão do caso Damião Ximenes Lopes vs. Brasil, na Corte Interamericana de Direitos Humanos), utilizando-se do método dedutivo e do procedimento estruturalista, com a finalidade de encontrar subsídios teóricos que contribuam para a melhor compreensão do tema, bem como verificar a sua aplicação.

O estudo encontra-se dividido em três momentos. Inicialmente são tecidas considerações preliminares sobre o tema, pautadas na questão evolutiva da compreensão dos direitos fundamentais e, especialmente, do tratamento dispensado a tais direitos na Constituição Federal de 1988. Após, analisam-se os direitos fundamentais, seus status e suas dimensões subjetiva e objetiva, abordando-se o dever de proteção, apurando sobre seus significados e abrangência. Por fim, abordam-se as possíveis contribuições sobre o dever de proteção e os direitos fundamentais (especialmente sobre 
sua concretização e a implementação de políticas públicas para alcançar tal objetivo) extraídas do julgamento do caso de Damião Ximenes Lopes, na Corte Interamericana de Direitos Humanos.

Assim, neste estudo pretende-se apresentar subsídios teóricos que possam contribuir para uma melhor compreensão do tema, a partir de sua aplicação em caso concreto, bem como das possibilidades que a noção de dever de proteção estatal oferece em termos de implementação de Políticas Públicas voltadas a uma efetiva realização dos direitos humanos e fundamentais.

\section{Direitos fundamentais e a constituição federal: considerações preliminares}

A Constituição não é simplesmente uma soma de direitos e de normas organizatórias, mas uma unidade de sentido que, serve de referencial para decisões de valor (associadas aos direitos fundamentais), de maneira que, para sua efetivação, os direitos fundamentais precisam ser percebidos, necessariamente, em sua relação com os demais conteúdos e princípios estruturais nela insculpidos (LEAL, 2007, p. 71).

Nesse contexto, Alexy (1999, p. 63) refere que constituições modernas dão aos direitos fundamentais, em geral, a força de concretização suprema, e quando elas não o fazem deveriam ser interpretadas nesse sentido ou, quando isso não fosse possível, modificadas.

Então, tem-se que no constitucionalismo democrático há uma relação indissociável entre os direitos fundamentais, Constituição e Estado de Direitos (SARLET, 2010, p. 58). Os direitos fundamentais integram, ao lado da definição da forma de Estado, do sistema de governo e da organização dos poderes, a essência do Estado constitucional, e por isso é elemento nuclear da Constituição material (SARLET, 2010, p. 58).

A importância dos direitos fundamentais para a construção e formação do constitucionalismo contemporâneo é percebível, pois são complementares e inseparáveis. Sobre essa relação, Perez Luño (2005, p. 19) cita que: "el constitucionalismo actual no sería lo que es sin derechos fundamentales." E que: "las normas que sancionan el estatuto de los derechos fundamentales, junto a aquéllas que consagran la forma de Estado y las que establecen el sistema económico, son las decisivas para definir el modelo constitucional de sociedad."

O modelo constitucional está notadamente fundado nos direitos fundamentais, em razão da importância que possuem para a sociedade. Perez Luño (2005, p. 20) menciona também que: " $L a$ concepción de los derechos fundamentales determina, de este modo, la propia significación del poder público, al existir una intima relación entre el papel asignado a tales derechos y el modelo de organizar y ejercer las funciones estatales." (PEREZ LUÑO, 2005, p. 20).

Então, a função do Poder Público deve ser vista em consonância com tal entendimento dos direitos fundamentais, o que significa dizer que a maneira de atuar do Estado está diretamente vinculada ao papel e à forma de interpretação que é dispensada a tais direitos. 
No Brasil, a Constituição vigente elenca os direitos fundamentais em seu Título II, nele trazendo o direito à vida, liberdade, dignidade, privacidade, etc. Mas, da análise em geral da Constituição, percebe-se que ela carrega um rol extremamente amplo e que não fica restrito unicamente a um artigo. Isso significa que o legislador constituinte não teve preocupação em limitar o texto, o que reflete diretamente a intenção e a importância que se quis dar a tais direitos.

A elaboração da Constituição tem estrita vinculação com a formatação do catálogo dos direitos fundamentais na nova ordem constitucional, especialmente pela circunstância resultante de um processo de redemocratização do País, após mais de 20 anos de ditadura militar (SARLET, 2010).

A Constituição da República Federativa do Brasil é classificada como uma Constituição rígida, e, por isso, há limites para a sua modificação. E a supremacia da Constituição e dos direitos fundamentais no ordenamento jurídico é, então, o fundamento dessa rigidez. Isso porque tal supremacia significa que "a constituição se coloca no vértice do sistema jurídico do país, o que confere validade, e que todos os poderes estatais são legítimos na medida em que ela os recomeça e na proporção por ela distribuídos." (SILVA, 2011, p. 45). Essa supremacia decorre do fato de que ela estrutura e organiza o próprio Estado, bem como porque estabelece as normas fundamentais desse Estado.

A positivação de direitos não se limita aos textos constitucionais do artigo $5^{\circ}$ e $6^{\circ}$, embora sejam os que contenham maior número, pois em seu texto, constantemente, são apresentados outros direitos, como os direitos dos trabalhadores (artigo $7^{\circ}$ ), das crianças e adolescentes (artigo 227), do meio ambiente (artigo 225), e muitos outros mais.

Além disso, há uma abertura do catálogo dos direitos fundamentais, estabelecida pelo $\$ 2^{\circ}$ do art. $5^{\circ}$, ao mencionar que os direitos e garantias expressos na Constituição não excluem outros decorrentes do regime e dos princípios por ela adotados, ou dos tratados internacionais de que o Brasil seja parte. Disso resulta o posicionamento de Sarlet (2010, p. 81), que aponta ainda que:

outra questão crucial decorrente da abertura material do catálogo reside na dificuldade em identificar, no texto constitucional (ou mesmo fora dele), quais os direitos - e aqui deixamos de adentrar o terreno espinhoso da conceituação do termo "direitos" - que efetivamente reúnem as condições para poder ser considerados materialmente fundamentais.

Para Sarlet (2010), então, a abertura gera dificuldade de compreender quais direitos efetivamente são fundamentais. Daí porque cogitar duas espécies de direitos fundamentais: direitos formal e materialmente fundamentais (ancorados na Constituição formal); e direitos apenas materialmente fundamentais (sem assento no texto constitucional).

Da mesma forma, Mendes (1999) menciona que a Constituição de 1988 atribuiu significado ímpar aos direitos individuais, e isso seria perceptível desde a colocação do catálogo dos direitos fundamentais no início do texto constitucional, ao contrário das Constituições anteriores, em que eles sempre constavam no final. E destaca-se que, ao lado da ampliação do rol, há uma potencialização da própria dimensão atribuída aos direitos individuais. 
Mas basta um texto constitucional para a garantia e promoção dos direitos nela consagrados? Parece que não, embora tal consagração deva ser festejada, pois já representa avanço. Isso porque, mesmo na vigência da Constituição, violações de direitos e falta de proteção ocorrem - a exemplo do caso de Damião Ximenes Lopes.

E, nessa perspectiva, o legislador e os demais órgãos com poderes normativos, judiciais ou administrativos cumprem uma importante tarefa na realização dos direitos fundamentais. E, sendo uma consequência do modelo de desenvolvimento brasileiro a geração de uma distribuição de direitos desigual no País, inclusive na distribuição de direitos tais como saúde, educação, trabalho, habitação (LEAL, 2000), há que se pensar em formas de melhor realizá-los.

Por fim, Leal (2000, p. 19) sustenta que:

[...] a implementação e a concretização dos Direitos Humanos e Fundamentais exigem uma democracia material e cotidiana, pois apenas nesta os requisitos da dignidade humana poderão ser verdadeiramente preenchidos, já que, em tese, só estão os indivíduos estarão subtraídos, não apenas ao arbítrio do poder político, mas também às coações derivadas do poder econômico e social.

Vale dizer que a realização efetiva dos direitos fundamentais depende de uma democracia real, do exercício da cidadania e de ação do poder político voltadas para essa finalidade, pois, como mencionado por Leal (2000), a dignidade da pessoa humana somente será atingida quando o indivíduo estiver protegido das coações advindas dos poderes políticos, econômicos e social.

\section{Dimensão objetiva dos direitos fundamentais e dever de proteção estatal}

Ao mesmo tempo em que os direitos fundamentais são direitos do cidadão, também representam um dever para o Estado. Isso porque o Estado precisa proteger e adotar ações para viabilizar a realização desses direitos.

Acerca desse tema, inicialmente cabe analisar a classificação de Jellinek (1905), segundo a qual haveria quatro status das reações entre indivíduo e Estado. ${ }^{3} \mathrm{O}$ status passivo refere-se à situação em que o indivíduo está subordinado à vontade do Estado. $O$ status negativo diz respeito ao direito do indivíduo de que o Estado não faça alguma coisa. O status positivo relaciona-se com o direito de o indivíduo ter uma prestação ou uma ação do Estado. E o status ativo refere-se à possibilidade de participação do indivíduo no poder estatal. ${ }^{4}$

\footnotetext{
3 A análise dessa teoria é imprescindível, pois, como afirma Sarmento (2004, p. 359): "A doutrina moderna dos direitos fundamentais tem raízes na influente teoria dos direitos públicos subjetivos elaborada por George Jelliek no final do século XIX, em obra clássica intitulada Sistema dos Direitos Públicos Subjetivos."

4 Para Sarmento (2004, p. 139): "A teoria de Jelinek concebia os direitos a partir de uma perspectiva exclusivamente subjetiva, o que era natural considerando a ambiência cultural da época, em que o paradigma jurídico reinante era ainda o Estado Liberal. As primeiras fissuras nesta concepção individualista dos direitos fundamentais remontam ao constitucionalismo de Weimar, em especial à teoria das garantias institucionais, elaborada por Martin Wolf e Carl Schmitt, e a teoria da Constituição como integração, de Rudolf Smend."
} 
Nesse sentindo, não bastaria saber se um determinado direito fundamental está rotulado como "individual" ou "social" ou "político", mas também sob qual dos status (negativo, positivo ou ativo) ele pode ser subsumido, visto que se pode retirar as consequências jurídicas a respeito da concretização ou efetivação desse direito fundamental (BITENCOURT, 2013).

Para Brugger e Leal (2007), na maioria dos Estados ocidentais, a principal função dos direitos humanos e fundamentais é "negativa", o que significa que esses direitos são dirigidos contra eventuais abusos de poder, contra a tirania e contra a soberania absoluta, impondo limites ao poder e aos governos. E essa função tem suas justificativas impregnadas na própria história, seja por ser um resultado das próprias ideias do modelo Liberal, seja pela forma com que as intervenções do Estado se mostraram para a sociedade. ${ }^{5}$

Mas os direitos fundamentais não se limitam à função precípua de serem direitos subjetivos de defesa do indivíduo contra atos do poder público, mas também "constituem decisões valorativas de natureza jurídico-objetiva da Constituição, com eficácia em todo o ordenamento jurídico, sendo diretrizes para o legislativo, judiciário e executivo." (SARLET, 2010, p. 143).

Nesse sentido, o contraponto à ideia clássica dos direitos fundamentais é o direito a "uma ação positiva do Estado, que pertencem ao status positivo, mais precisamente ao status positivo em sentido estrito." (ALEXY, 2008, p. 433).

Então, Gavara de Cara (2010, p. 19) diferencia os direitos de defesa dos direitos a prestações, mencionando que:

la distinción entre derechos de defensa y derechos de prestación atiende fundamentalmente al contenido prescriptivo que encierran los correspondientes derechos fundamentales, es decir, a las obligaciones, deberes o prescripciones que deben cumplir los titulares de los destinatarios de los derechos fundamentales a favor de los titulares de los derechos.

Como mencionado pelo autor, a diferenciação passa pelo conteúdo prescritivo dos direitos fundamentais para seus destinatários, ou seja, pelas obrigações, deveres e prescrições que devem ser cumpridas em favor dos titulares de tais direitos. Com isso, a prestação pode ocorrer de formas diferentes, mas que são complementares. Alexy (2008, p. 442) entende que:

a escala de ações estatais positivas que podem ser objeto de um direito a prestação estende-se desde a proteção do cidadão contra outros cidadãos por meio de normas de direito penal, passa pelo estabelecimento de normas organizacionais e procedimentais e alcança até prestações em dinheiro e outros bens.

Para o autor, as ações estatais podem assumir diferentes sentidos quando relacionadas a um direito à prestação. Nesse sentido, "os direitos a prestações (em sentido amplo) podem ser dividi-

\footnotetext{
5 Grinover (2013, p. 126) menciona que "ao dever de abstenção do Estado substitui-se seu dever a um dare, facere, praestare, por intermédio de uma atuação positiva, que realmente permita a fruição dos direitos de liberdade da primeira geração, assim como dos novos direitos."
} 
dos em três grupos: (1) direitos a proteção; (2) direitos a organização e procedimento; e (3) direitos a prestações em sentido estrito." (ALEXY, 2008, p. 444).

Gavara de Cara (2010, p. 20), discorrendo sobre as implicações dos direitos a prestações, também menciona que:

los derechos de prestación implican una heterogeneidad de criterios materiales y factuales de realización que pueden ir desde la protección de la garantía de plazas escolares gratuitas, al ingreso o acceso a las instituciones públicas, a un minimo de existencia, a la configuración de estructuras organizativas y procedimentales para ejercer derechos, hasta el desarrollo de medidas normativas adoptadas por los poderes públicos frente a coacciones de terceras personas, es decir, adopción de medidas por parte del Estado para la resolución de colisiones entre derechos.

Destarte, o direito a prestações assume diferentes nortes, abrangendo o de proteção, que pode ser entendido como os direitos do titular de direitos fundamentais em face do Estado a que este o proteja contra intervenções de terceiros (ALEXY, 2008). Significa que para uma efetiva prestação, o Estado deve proteger, e essa proteção pode ocorrer, por exemplo, por meio de uma legislação específica, como citado por Alexy (2008), quando refere às normas penais que protegem o cidadão contra outros cidadãos. Significa dizer que o Estado, para poder proteger alguém de um homicídio, precisa inicialmente dizer, por intermédio da legislação, que essa conduta não é aceita e que quem infringi-la estará sujeito às penalidades previstas.

Mas as prestações do Estado também devem pautar-se por uma organização e definição dos procedimentos pelos quais prestará determinado direito. Aqui, parece possível exemplificar-se, por meio do direito à educação, sendo necessário que o Estado defina e organize como será disponibilizado o ensino, estabelecendo quem presta (se público ou privado), quem deve ter acesso, e como deve funcionar o sistema.

Nesse sentido, Mendes (2010, p. 8) também refere que:

isto se aplica de imediato aos direitos fundamentais que têm por objeto a garantia dos postulados da organização e do procedimento, como é o caso da liberdade de associação (CF, art. $5^{\circ}$, XVII), das garantias processuais-constitucionais da defesa e do contraditório (art. $5^{\circ}, \mathrm{LV}$ ), do direito ao juiz natural (art. $5^{\circ}$, XXXVII), das garantias processuais-constitucionais de caráter penal (inadmissibilidade da prova ilícita, o direito do acusado ao silêncio e à não-auto-incriminação, etc.). Também poder-se-ia cogitar aqui da inclusão, no grupo dos direitos de participação na organização e procedimento, do direito dos partidos políticos a recursos do fundo partidário e do acesso à propaganda política gratuita nos meios de comunicação (art. $17 \$ 3^{\circ} \mathrm{da} \mathrm{CF}$ ), na medida em que se trata de prestações dirigidas tanto à manutenção da estrutura organizacional dos partidos (e até mesmo de sua própria existência como instituições de importância vital para a democracia), quanto à garantia de uma igualdade de oportunidades no que concerne à participação no processo democrático.

Ainda, o direito à prestação abarca a prestação em espécie, quando se disponibiliza dinheiro ou bens para o cidadão, como no caso dos benefícios assistenciais, que pretendem, através de determinado valor, dar um suporte financeiro para aqueles que preenchem determinados requisitos legais. 
Então, consoante o entendimento de Alexy (1999, p. 59), a concepção atual dos direitos fundamentais se caracteriza por uma dupla qualificação de direitos: "concebe-se como direitos subjetivos de liberdade, dirigidos ao Estado, e como normas objetivas de princípios ou decisões valorativas que tem validez para todos os âmbitos do direito."

Novais (2003, p. 53) considera que, para além da sua dimensão subjetiva, os direitos fundamentais constituem, no seu conjunto, "um sistema ou ordem objetiva de valores que legitima a ordem jurídico-constitucional do Estado, que condiciona constitutivamente toda a atuação dos poderes constituídos e que irradia uma força expansiva a todos os ramos do direito."

Por sua vez, os direitos subjetivos seriam sempre reflexo de uma posição jurídica, e isso implicaria dizer que todo direito subjetivo possui subjetividade e implica um poder ou uma faculdade para a realização efetiva de interesses que são reconhecidos por uma norma jurídica como próprios do respectivo titular (NOVAIS, 2003).

A doutrina da dimensão objetiva dos direitos fundamentais nasce no direito alemão a partir da decisão do Tribunal Constitucional Federal Alemão no caso Lüth, ${ }^{6}$ em 1958, com a ideia de direitos fundamentais como decisões valorativas de cunho objetivo da Constituição, espraiando sua eficácia sobre todo o direito positivo, de modo a orientar o exercício das funções legislativa, administrativa e judiciária (BverfGE 7, 198).

Sarmento (2004) entende que a consagração explícita da dimensão objetiva dos direitos fundamentais só ocorrerá sob a égide da Lei Fundamental de Bonn, e o marco essencial seria, sem dúvida, o julgamento do caso Lüth, pela Corte Constitucional germânica.

Notadamente que a questão se tornou alvo de grandes debates na doutrina e na jurisprudência alemã, e com ela surgiram conceitos e ideias importantes sobre os direitos fundamentais. Leal (2007, p. 66) menciona que "assim, em cada decisão, é preciso que o juiz teste a força do discurso positivo constitucional para determinar se e até que ponto a lei aplicável deve ser influenciada e limitada por essa mesma esfera valorativa."

As leis precisam ser interpretadas, de acordo com esse entendimento, pelos direitos fundamentais, cujo conteúdo de valor deve ser protegido, inclusive nas relações jurídico-privadas. Exemplo disso ocorreu no citado caso Lüth, quando o exercício dos direitos subjetivos individuais é condicionado ao interesse comunitário prevalente. E tal decisão do Tribunal alemão traz três aspectos destacáveis, dentre os quais, "a compreensão dos direitos como ordem objetiva de valores, a ideia de

\footnotetext{
6 Tratava-se de discussão relativa à legitimidade de um boicote contra um filme dirigido pelo cineasta Veit Harlan, de passado nazista, organizado pelo Presidente do Clube de Imprensa de Hamburgo, Erich Lüth, em 1950. A produtora e a distribuidora do filme insurgiram-se contra o boicote e obtiveram decisão injuntiva da Justiça Estadual de Hamburgo, determinando sua cessação, com base no art. 826 do Código Civil alemão, segundo o qual "quem causar danos intencionais outrem, e de maneira ofensiva aos bons costumes, fica obrigado a compensar o dano." Irresignado com o julgamento, Lüth interpôs queixa constitucional (Verfassungsbeschwerde) para o Tribunal Constitucional. Este acolheu o recurso, fundamentando-se no entendimento de que cláusulas gerais do direito privado, como os "bons costumes" referidos no art. 826 do BGB, têm de ser interpretados ao lume da ordem de valores sobre a qual se assenta a Constituição, levando em consideração os direitos fundamentais, o que não fora feito pela Corte de Hamburgo (SARMENTO, 2004, p. 141).
} 
que os direitos fundamentais vinculam os três poderes como princípios, e a possibilidade de colisão entre valores." (LEAL, 2007, p. 68).

Na França não se desenvolveu dogmaticamente a ideia de dimensão objetiva dos direitos fundamentais, mas o caso do lançamento de anões, julgado pelo Conselho de Estado, pode demonstrar essa teoria, pois trata da típica hipótese de que um conceito jurídico indeterminado (ordem pública) é interpretado no sentido de promoção dos direitos fundamentais e do princípio da dignidade da pessoa humana (SARMENTO, 2004).

Sarmento (2004, p. 159) relata que:

na cidade de Morsang-sur-Orge, na Riviera francesa, uma boate organizara um grotesco concurso de lançamento de anão: sagrava-se o vencedor da prova o cliente que conseguisse arremessar o anão mais longe, a partir do placo da discoteca. $\bigcirc$ prefeito interditou o espetáculo, exercitando seu poder de polícia fundamentado na tutela da "ordem pública". Inconformados, a boate e o anão - este revoltado porque perdera o emprego - impugnaram o ato administrativo em questão, mas o Conselho do Estado, em solução definitiva da causa, manteve a decisão, criando o precedente no sentido de que o princípio da dignidade da pessoa humana condiciona a interpretação do conceito jurídico indeterminado de "ordem pública".

A dignidade da pessoa humana assume, então, dupla interpretação e aplicação, uma que garante o direito de liberdade do indivíduo, e outra que relaciona e vincula o Estado, no sentido de garantir as condições para que essa dignidade possa existir, ou ser preservada. Nesse norte, o caso remete à análise de que os direitos violados representam valores fundamentais para a comunidade, e que não são vistos apenas sob a visão individualista, mas também social.

Sobre essa diferenciação entre dimensão objetiva e subjetiva dos direitos fundamentais, Perez Luño (2005, p. 21) menciona que: "los derechos fundamentales han dejado de ser meros limites al ejercicio del poder político, o sea, garantías negativas de los intereses individuales, para devenir un conjunto de valores o fines directivos de la acción positiva de los poderes públicos."

Segundo o autor, os direitos fundamentais passam a ser não apenas limites ao exercício do Poder Político, tidos como garantias negativas dos interesses individuais, pois se tornam um conjunto de valores que norteiam a ação positiva dos poderes públicos.

Os direitos fundamentais apresentam a característica de direitos subjetivos, que representa uma liberdade individual e a oponibilidade em face do Estado. Por sua vez, o caráter objetivo dos direitos fundamentais está ligado ao direito do indivíduo, considerado titular do direito. E a dimensão objetiva seria o alicerce, inclusive, para a consolidação de um Estado Democrático de Direito.

Dito isso, a dimensão objetiva, e especialmente seu conteúdo, "configura uma variação incontrastavelmente qualitativa, o rompimento e a mudança da relação direta, exclusiva e unidimensional do cidadão com o Estado." (BONAVIDES, 2009, p. 602).

a) a irradiação e a propagação dos direitos fundamentais a toda a esfera do Direito Privado; em rigor, a todas as províncias do Direito, sejam jusprivatistas, sejam juspublicísticas; b) a elevação de tais direitos à categoria de princípios, de tal sorte que se convertem no mais importante polo de eficácia normativa da Constitui- 
ção; c) a eficácia vinculante, cada vez mais enérgica e extensa, com respeito aos três Poderes, nomeadamente o Legislativo; d) a aplicabilidade direta e a eficácia imediata dos direitos fundamentais, com perda do caráter de normas programáticas; e) a dimensão axiológica, mediante a qual os direitos fundamentais aparecem como postulados sociais que exprimem uma determinada ordem de valores e ao mesmo passo servem de inspiração, impulso e diretriz para a legislação, a administração e a jurisdição; f) o desenvolvimento da eficácia inter-privatos, ou seja, em relação a terceiros (Drittwirkung), com atuação no campo dos poderes sociais, fora, portanto, da órbita propriamente dita do Poder Público ou do Estado, dissolvendo, assim, a exclusividade do confronto subjetivo imediato entre o direito individual e a máquina estatal; confronto do qual, nessa qualificação, os direitos fundamentais se desataram; g) a aquisição de um "duplo caráter" (Doppelcharakter, Doppelgestalt ou Doppelqualifierung), ou seja, os direitos fundamentais conservam a dimensão subjetiva - da qual nunca se podem apartar, pois, se o fizessem, perderiam parte de sua essencialidade - e recebem um aditivo, uma nova qualidade, um novo feitio, que é a dimensão objetiva, dotada de conteúdo valorativo-decisório, e de função protetora tão excelentemente assinalada pelos publicistas e juízes constitucionais da Alemanha; h) a elaboração do conceito de concretização, de grau constitucional, de que se têm valido, com assiduidade, os tribunais constitucionais do Velho Mundo na sua construção jurisprudencial em matéria de direitos fundamentais; i) o emprego do princípio da proporcionalidade vinculado à hermenêutica concretizante, emprego não raro abusivo, de que derivam graves riscos para o equilíbrio dos Poderes, com os membros da judicatura constitucional desempenhando de fato e de maneira insólita o papel de legisladores constituintes paralelos, sem todavia possuírem, para tanto, o indeclinável título de legitimidade; e j) a introdução do conceito de pré-compreensão (Vorverständnis), sem o qual não há concretização. (BONAVIDES, 2009, p. 603-604).

Disso tudo resulta a relevância que o reconhecimento da dimensão objetiva pode trazer para o ordenamento jurídico, pois traz consigo a ideia de que os direitos fundamentais assumem uma função irradiante sobre as demais normas. Além disso, nessa visão há a elevação de tais direitos ao patamar de princípios, a eficácia vinculante e imediata, a aplicabilidade direta e a sua relação com a sociedade, com a necessidade de concretização e de observância da proporcionalidade.

O dever de proteção envolve a atividade legislativa, administrativa e jurisdicional do Estado, e é um dos mais importantes desdobramentos da teoria contemporânea dos direitos fundamentais - dimensão objetiva - em que o Estado é uma instituição necessária para a própria garantia desses direitos na sociedade civil (SARMENTO, 2004).

Além disso, Conforme Mendes (2010), nos termos da doutrina e com base na jurisprudência da Corte Constitucional alemã, pode-se estabelecer a seguinte classificação do dever de proteção:

a) Dever de proibição (Verbotspflicht), consistente no dever de se proibir determinada conduta; b) Dever de segurança (Sicherheitspflicht), que impõe ao Estado o dever de proteger o indivíduo contra ataques de terceiros mediante a adoção de medidas diversas; c) Dever de evitar riscos (Risikopflicht), que autoriza o Estado a atuar com objetivo de evitar riscos para o cidadão em geral mediante a adoção de medidas de proteção ou de prevenção especialmente em relação ao desenvolvimento técnico ou tecnológico. (MENDES, 2010).

E, por assim ser, a não observância de um dever de proteção acaba por corresponder a uma lesão a direito fundamental. Na Alemanha, em caso emblemático sobre direito à vida e descriminali- 
zação do abordo, a Corte Constitucional germânica aplicou a teoria do dever de proteção, no sentido de que o Estado não só não pode intervir no desenvolvimento da vida, mas também deveria agir protetivo. A proteção dos direitos fundamentais é compreendida sob dois enfoques, um deles como proibição de excesso (Übermassverbot), ou seja, de intervenções, e o outro como proibição de proteção insuficiente (Untermassverbot), ou seja, de omissão. Na ocasião, a Corte, fazendo uma ponderação pautada pelo princípio da dignidade da pessoa humana, entendeu que a descriminalização do aborto violaria o dever de proteção à vida. ${ }^{7}$

A teoria da dimensão objetiva dos direitos fundamentais não impõe a necessidade de que a Constituição estabeleça, expressamente, os deveres ao Estado, mas da análise do texto constitucional encontram-se diversos dispositivos que estabelecem expressamente o dever do Estado em garantir determinados direitos aos cidadãos. ${ }^{8}$ Veja-se, a título de exemplo, alguns desses direitos:

Quadro 1 - Exemplos de direitos dos cidadãos

\begin{tabular}{|c|c|c|}
\hline Direito & Artigo & Redação \\
\hline $\begin{array}{l}\text { Segurança } \\
\text { Pública }\end{array}$ & 144 & $\begin{array}{l}\text { A segurança pública, dever do Estado, direito e responsabilidade de todos, é exercida para a preser- } \\
\text { vação da ordem pública e da incolumidade das pessoas e do patrimônio [...] }\end{array}$ \\
\hline Saúde & 196 & $\begin{array}{l}\text { A saúde é direito de todos e dever do Estado, garantido mediante políticas sociais e econômicas que } \\
\text { visem à redução do risco de doença e de outros agravos e ao acesso universal e igualitário às ações e } \\
\text { serviços para sua promoção, proteção e recuperação }\end{array}$ \\
\hline Educação & 205 & $\begin{array}{l}\text { A educação, direito de todos e dever do Estado e da família, será promovida e incentivada com a } \\
\text { colaboração da sociedade, visando ao pleno desenvolvimento da pessoa, seu preparo para o exercício } \\
\text { da cidadania e sua qualificação para o trabalho. }\end{array}$ \\
\hline Esporte & 217 & É dever do Estado fomentar práticas desportivas formais e não formais, como direito de cada um. \\
\hline $\begin{array}{l}\text { Meio am- } \\
\text { biente }\end{array}$ & 225 & $\begin{array}{l}\text { Todos têm direito ao meio ambiente ecologicamente equilibrado, bem de uso comum do povo e es- } \\
\text { sencial à sadia qualidade de vida, impondo-se ao Poder Público e à coletividade o dever de defendê-lo } \\
\text { e preservá-lo para as presentes e futuras gerações. }\end{array}$ \\
\hline $\begin{array}{l}\text { Direitos da } \\
\text { criança e do } \\
\text { adolescente }\end{array}$ & 227 & $\begin{array}{l}\text { É dever da família, da sociedade e do Estado assegurar à criança, ao adolescente e ao jovem, com } \\
\text { absoluta prioridade, o direito à vida, à saúde, à alimentação, à educação, ao lazer, à profissionali- } \\
\text { zação, à cultura, à dignidade, ao respeito, à liberdade e à convivência familiar e comunitária, além } \\
\text { de colocá-los a salvo de toda forma de negligência, discriminação, exploração, violência, crueldade } \\
\text { e opressão. }\end{array}$ \\
\hline
\end{tabular}

Verificada a maneira de tratamento dos direitos fundamentais pela Constituição Federal e, da mesma forma, sobre o dever de promoção e realização de tais direitos pelo Estado, analisa-se o caso de Damião Ximenes Lopes, pois mesmo diante da consagração do princípio da Dignidade da

\footnotetext{
7 Sarmento (2010, p. 164), refere que: "Cumpre destacar que esta orientação jurisprudencial foi posteriormente flexibilizada pela Corte Constitucional alemã, no julgamento do caso que ficou conhecido como Aborto II, proferido em 1993. No novo julgado, o Tribunal decidiu que embora o aborto continuasse sendo contrário à Constituição daquele país, o legislador poderia optar pela adoção de outras medidas para a proteção do direito à vida do feto, ao invés da criminalização da conduta da mãe. E menciona ainda que "Outro caso importante e verdadeiramente dramático julgado pela Corte Constitucional alemã, em que entrou em questão a teoria dos deveres de proteção, foi o que envolveu o sequestro do industrial Hans Martin Schleyer, e, 1977, por terroristas que, depois de assassinarem os quatro empregados que estavam com ele, exigiram, para não o matarem, a libertação de onze companheiros presos, pertencentes à mesma organização criminosa. Diante da recusa do governo em atender à exigência dos terroristas, o filho do industrial interpôs queixa constitucional à Corte, alegando que, ao não atender as exigências dos sequestradores, o Estado estava praticamente condenando seu pai à morte."

8 Sarmento (2004, p. 167-168) esclarece que no Brasil, parece indiscutível a possibilidade de aplicação da teoria do dever de proteção, diante da moldura axiológica delineada pela Constituição de 1988.
} 
Pessoa Humana e dos direitos à saúde e vida, o caso estampa a violação de tais direitos e a ausência de proteção do Estado.

\section{Como a Corte Interamericana de Direitos Humanos percebe o dever de proteção? Alguns apontamentos a partir da decisão do caso Damião Ximenes Lopes vs. Brasil}

Como mencionado supra, o tema do dever de proteção nasce da teoria da dimensão objetiva dos direitos fundamentais. Contudo, sua aplicação prática é tema emblemático, especialmente no que se refere ao que compreende tal dever e em quais situações deve ser aplicado.

Por isso, para analisar o problema que permeia este estudo, torna-se pertinente estudar o caso Damião Ximenes Lopes versus Brasil, julgado pela Corte Interamericana de Direitos Humanos, pois analisou, entre outros temas, o dever de proteção dos direitos fundamentais, sendo que as considerações tecidas podem contribuir para a elucidação do entendimento da referida Corte.

Inicialmente cabe lembrar que o caso teve sentença no ano 2006 e discutia a violação de direitos humanos (integridade física, vida, garantias judiciais e proteção judicial) pelo Brasil, em razão de fatos ocorridos (inclusive a morte) durante a internação do paciente Damião Ximenes Lopes, com deficiência mental, na Casa de Repouso Guararapes no Município de Sobral, Estado do Ceará.

Consoante a decisão, a contenção física utilizada pelos profissionais da entidade teria resultado em lesões no paciente, além de ter sido ele submetido a maus-tratos, com condições de confinamento desumanas e degradantes. Também foi ressaltada a ausência de médico na casa de repouso no momento de seu falecimento, não tendo sido prestada a Damião Ximenes Lopes a assistência adequada.

A Casa de Repouso Guararapes, hospital privado de saúde, foi contratada pelo Estado para prestar serviços de atendimento psiquiátrico, sob a direção do Sistema Único de Saúde e como unidade pública de saúde, em nome e por conta do Estado.

$\mathrm{Na}$ análise do caso ficou consignado também que o Estado conhecia as condições de internação que a Casa de Repouso Guararapes oferecia na época dos fatos e que a obrigação de garantir os direitos humanos consagrados na Convenção não se esgota na existência de uma ordem normativa destinada a tornar possível o cumprimento dessa obrigação, mas compreende a necessidade de uma conduta governamental que assegure a existência, na realidade, de uma eficaz garantia do livre e pleno exercício dos direitos humanos.

Além disso, considerou-se, também, que não foram disponibilizados os meios de acesso à justiça, de investigação e processamento do caso em prazo razoável (uma vez que, após mais de seis anos de iniciado, ainda não havia sido proferida sentença de primeira instância). Tais fatos fizeram com a família da vítima sofresse ainda mais, pois sequer conseguiam ver os fatos devidamente apurados.

A sentença reconheceu a responsabilidade do Brasil, mesmo com a delegação dos serviços de saúde a entidades privadas, ressaltando que as pessoas com deficiência exigem uma atenção especial do 
Estado na promoção de seus direitos, e o condenou à reparação de danos a familiares, bem como exigiu a publicação da sentença, a investigação dos fatos e o estabelecimento de programas de capacitação.

A relevância da sentença encontra-se em determinar medidas que objetivam melhorar as condições de atendimento para pessoas com problemas mentais, tanto que determinou que o Estado deve continuar a desenvolver um programa de formação e capacitação para o pessoal médico, de psiquiatria e psicologia, de enfermagem e auxiliares de enfermagem e para todas as pessoas vinculadas ao atendimento de saúde mental, em especial sobre os princípios que devem reger o trato das pessoas portadoras de deficiência mental, conforme os padrões internacionais.

O Brasil pagou as indenizações fixadas pela Corte e avançou em relação às políticas públicas voltadas para o atendimento de pessoas portadoras de deficiência mental e de funcionamento de instituições psiquiátricas. Porém, tal marco não foi capaz de desenvolver de forma mais efetiva a proteção do Estado aos direitos fundamentais, tanto que ainda hoje se noticiam outras violações e omissões - como na saúde, educação e segurança pública.

Mas mesmo que não se encontre referência expressa à teoria do dever de proteção na decisão em comento, constata-se que as medidas adotadas especialmente na ideia de que o país não proporcionou uma proteção efetiva a Damião e, posteriormente, para sua família, encontram-se atreladas às ideias centrais de dita teoria.

E, por isso, ainda persiste a necessidade de entender a responsabilidade estatal, e no que se refere ao tema objeto deste estudo, interessante destacar alguns elementos encontrados na sentença. Assim, na decisão destacou-se que "a Corte, ademais, dispôs que a responsabilidade estatal também pode ser gerada por atos de particulares em princípio não atribuíveis ao Estado." (CORTE INTERAMERICANA DE DIREITOS HUMANOS, 2006, p. 25). Além disso:

As obrigações erga omnes que têm os Estados de respeitar e garantir as normas de proteção e de assegurar efetividade dos direitos projetam seus efeitos para além da relação entre seus agentes e as pessoas submetidas a sua jurisdição, porquanto se manifestam na obrigação positiva do Estado de adotar as medidas necessárias para assegurar a efetiva proteção dos direitos humanos nas relações interindividuais. (CORTE INTERAMERICANA DE DIREITOS HUMANOS, 2006, p. 25).

Nesse sentido, consoante entendimento expressado, as hipóteses de responsabilidade estatal por violação dos direitos previstos na Convenção Americana dos Direitos Humanos podem ser tanto por ações ou omissões, inclusive quando a omissão resulta em evitar que terceiros violem os bens jurídicos.

Cabe lembrar que no caso analisado se trata de entidade privada que estava autorizada a prestar serviço que originariamente caberia ao Estado. E nesse caso, o dever especial de proteção resultaria dos direitos à vida, à saúde e à integridade física, sendo que conforme ficou assentado:

A corte considera que os Estados têm o dever de regulamentar e fiscalizar toda a assistência de saúde prestada às pessoas sob sua jurisdição, como dever especial de proteção à vida e à integridade pessoal, independentemente de ser a entidade que 
presta esses serviços de caráter público ou privado. (CORTE INTERAMERICANA DE DIREITOS HUMANOS, 2006, p. 26).

Ademais, é entendimento da Corte Interamericana que todas as pessoas que se encontram em situação de vulnerabilidade são titulares de uma proteção especial, em virtude dos deveres especiais cujo cumprimento por parte do Estado é necessário para atender às obrigações gerais de respeito e garantia dos direitos humanos (CORTE INTERAMERICANA DE DIREITOS HUMANOS, 2006, p. 28).

Destacou-se que a Convenção Americana de Direitos Humanos estabelece claramente que:

Artigo 1.1: Os Estados Partes nesta Convenção comprometem-se a respeitar os direitos e liberdades nela reconhecidos e a garantir seu livre e pleno exercício a toda pessoa que esteja sujeita à sua jurisdição, sem discriminação alguma por motivo de raça, cor, sexo, idioma, religião, opiniões políticas ou de qualquer outra natureza, origem nacional ou social, posição econômica, nascimento ou qualquer outra condição social.

Parágrafo 1 do artigo 4: toda pessoa tem o direito de que se respeite sua vida. Esse direito deve ser protegido pela lei e, em geral, desde o momento da concepção. Ninguém pode ser privado da vida arbitrariamente.

Artigo 5: 1. Toda pessoa tem o direito de que se respeite sua integridade física, psíquica e moral. 2. Ninguém deve ser submetido a torturas, nem a penas ou tratos cruéis, desumanos ou degradantes. Toda pessoa privada da liberdade deve ser tratada com o respeito devido à dignidade inerente ao ser humano.

Logo, consubstancia-se, nos artigos em comento, o direito à vida, ao respeito e à integridade psíquica e moral de toda pessoa. Por outro lado, denota-se a obrigação/dever de proteção do Estado em relação a esses direitos, pois é pressuposto para o pleno exercício, sendo que em havendo a omissão do Estado nesse ponto, ditos direitos restam prejudicados, como sustentado no caso de Damião.

Além disso, o Art. 196 da Constituição Federal do Brasil estabelece expressamente que a saúde é direito de todos e dever do Estado, garantido mediante políticas sociais e econômicas que visem à redução do risco de doença e de outros agravos e ao acesso universal e igualitário às ações e serviços para sua promoção, proteção e recuperação.

E foi considerando isso e todo o sistema normativo existente, internacional e nacional, que a Corte Interamericana de Direitos Humanos entendeu que o Estado era responsável pela violação dos direitos humanos e que tinha o dever de proteger o senhor Damião Ximenes Lopes.

Conclui-se que, como bem esclarecido na referida sentença, a responsabilidade do Estado tanto por ações quanto omissões é resultado das obrigações constantes na Convenção e nas normas internas do País, bem como do fato de que a saúde é um bem público cuja proteção está a cargo dos Estados, visto que estes têm o dever de regulamentar e fiscalizar toda a assistência de saúde prestada às pessoas sob sua jurisdição, como dever especial de proteção à vida e à integridade pessoal, independentemente de ser a entidade que presta esses serviços de caráter público ou privado.

Destaca-se que a decisão não ficou limitada à reparação/indenização da família, mas também determinou a implementação de medidas com o objetivo de evitar que novas violações viessem 
a ocorrer, o que se compatibiliza com a dimensão objetiva dos direitos fundamentais, pois a violação ocorrida repercute em toda a sociedade, e a sentença, por conseguinte, analisa o direito não somente de Damião e sua família, mas de todo aquele que pode ter sonegada a proteção e efetivação dos mesmos direitos, pontuando-se o compromisso e o dever de proteção do Estado com toda a sociedade.

No entendimento de Sarmento (2004), a dimensão objetiva liga-se ao reconhecimento de que os direitos, além de imporem certas prestações aos poderes estatais, consagram também os valores mais importantes em uma comunidade política, e, como garantia de valores morais coletivos, os direitos fundamentais não são apenas um problema do Estado, mas de toda a sociedade.

Mas também é importante dizer que o reconhecimento da dimensão objetiva dos direitos fundamentais não significa desprezo à sua dimensão subjetiva, mas reforço/complemento a ela, conferindo proteção reforçada a tais direitos, mediante de esquemas que transcendem a estrutura relacional típica dos direitos subjetivos (SARMENTO, 2004, p. 136). Ou seja, não se deixa de analisar o caso e impor medidas reparatórias/indenizatórias para os autores da ação, mas ao mesmo tempo, ao reconhecer que o Estado falhou, determinam-se medidas que busquem trazer avanços sociais.

Gavara de Cara (2010, p. 12) discorre sobre isso quando refere que: "la dimensión objetiva de los derechos implica una lectura implícita de los derechos en términos de colectividades, es decidir, el impulso que general os bienes jurídicos protegidos [...]" Fala-se, sob essa perspectiva, de proteção aplicada a todos, em geral, como um contraponto ao tratamento individual, da posição jurídica subjetiva.

E conforme Mendes (1999, p. 36):

os direitos fundamentais são, a um só tempo, direitos subjetivos e elementos fundamentais da ordem constitucional objetiva. Enquanto direitos subjetivos, os direitos fundamentais outorgaram aos titulares a possibilidade de impor os seus interesses em face dos órgãos obrigatórios. Na sua dimensão como elemento fundamental da ordem constitucional objetiva, os direitos fundamentais - tanto aqueles que não asseguram, primariamente, um direito subjetivo, quando aqueloutros, concebidos como garantias individuais - forma a base do ordenamento jurídico de um Estado de Direito democrático.

E, admitindo-se a dimensão objetiva dos direitos fundamentais, e relembrando a classificação do dever de proteção que dela resulta, encontrar-se-ia o dever de proibição de condutas que de alguma forma violem os direitos fundamentais (notadamente, no caso de Damião, a vida, a dignidade e a integridade física), o dever de segurança contra terceiros (notadamente com fiscalização e proteção ao indivíduo que se encontra em situação de risco ou vulnerabilidade), e o de evitar riscos (desenvolvimento de capacitação e treinamento das pessoas que trabalham em hospitais e clínicas que atendem pessoas com deficiência mental).

Ainda, uma crítica destacável nesse aspecto é apresentada por Pereira (2003), quando menciona que a teoria dos deveres de proteção não se presta a explicar de forma completa e coerente a aplicação dos direitos fundamentais nas relações privadas. A autora refere que: 
Tal solução dogmática, ao transferir a responsabilidade pela violação ao direito fundamental sempre para o Estado - deslocando, assim, o problema do campo privado, para a esfera do direito público - põe em evidência o fato de que o reconhecimento da eficácia em face de particulares dos direitos fundamentais instaura uma crise na própria noção de direito público subjetivo [...] (PEREIRA, 2003, p. 178).

Reconhece-se, então, que há de se ter cautela na responsabilização do Estado quando a violação a direitos fundamentais seja praticada por particular, e nesse ponto não se discorda da autora. Contudo, também não pode o Estado se eximir da sua responsabilidade, ao menos de regular e de fiscalizar, como deveria ter ocorrido no caso de Damião Ximenes Lopes.

Por fim, reitera-se que a Corte desempenha um importante papel e que a consolidação da sua jurisdição é salutar para a proteção dos direitos e a responsabilização dos Estados que não os garantirem de forma eficaz.

Mesmo que de forma singela ou que os avanços práticos sejam poucos e vagarosos, a responsabilização do Estado no caso Ximenes Lopes e o posicionamento expressado pela Corte sobre o dever de proteção do Estado e, sobretudo, as medidas determinadas em sentença contribuem significativamente para a garantia de direitos e para a implementação de políticas públicas, em uma leitura de direitos fundamentais em termos de coletividade e que precisam ser protegidos de forma suficiente, o que engloba seu caráter normativo e material.

\section{Conclusão}

Diante dessas considerações, posicionamentos, legislações e do caso analisado é possível afirmar que a necessidade de preservação e de efetivação dos direitos fundamentais é resultado do modelo de Estado, da dimensão objetiva dos direitos fundamentais e da vontade constitucional, já que deu atenção especial a tais direitos e estabeleceu como fundamento da República Federativa do Brasil a dignidade da pessoa humana.

Assim, direitos como integridade física, vida, garantias judiciais e proteção judicial (objeto de análise no caso Ximenes Lopes) precisam ganhar atenção especial do Estado, em razão do reconhecimento do dever de proteção. E isso resulta do entendimento de que cabe ao Estado o dever de evitar toda forma de violação aos direitos fundamentais, visto que para tanto precisa agir, fiscalizar e regulamentar, sob pena de ser considerado também responsável pela violação.

Além disso, é possível constatar que a judicialização se torna uma consequência da omissão dos poderes políticos do Estado em cumprir com esse dever para com os titulares dos direitos, podendo repercutir, inclusive, no âmbito internacional, como ocorrido no caso analisado.

Por fim, destaca-se que a decisão da Corte Interamericana contribui para a análise do tema, no sentido de reconhecer a responsabilidade do Estado, já que este falhou enquanto garantidor e protetor de direitos fundamentais, bem como pela interpretação e aplicação das normas, em prol de garantir direitos tão importantes do ser humano. Ademais, a determinação de medidas que vão 
além das que repercutem diretamente nas pessoas envolvidas no caso, pois consideram o direito do indivíduo como titular do direito, ressalta a dimensão objetiva dada aos direitos fundamentais e a necessidade de pensar o direito coletivamente.

Reitera-se, assim, que a Corte desempenha um importante papel e que a consolidação da sua jurisdição é salutar para a proteção dos direitos e a responsabilização dos Estados que não os garantirem de forma eficaz. E, mesmo que os avanços práticos sejam poucos e vagarosos, a responsabilização do Estado no caso Ximenes Lopes e o posicionamento expressado pela Corte sobre o dever de proteção do Estado e, sobretudo, as medidas determinadas em sentença contribuem significativamente para a garantia de direitos e para a implementação de políticas públicas, em uma leitura de direitos fundamentais em termos de coletividade, que precisam ser protegidos de forma suficiente, o que engloba seu caráter normativo e material.

\section{Referências}

ALEXY, Robert. Teoria dos Direitos Fundamentais. São Paulo: Malheiros, 2008.

ALEXY, Robert. Direitos fundamentais no Estado Constitutional democrático: para a relação entre direitos do homem, direitos fundamentais, democracia e jurisdição constitucional. Tradução Luiz Afonso Heck. Revista de Direito Administrativo, Rio de Janeiro, n. 217, jul./set. 1999.

BITENCOURT, Caroline Muller. Controle jurisdicional de políticas públicas. Porto Alegre: Nuria Fabris, 2013.

BONAVIDES, Paulo. Curso de Direito Constitucional. 14. ed. São Paulo: Malheiros Editores, 2004.

BRUGGER, Winfried; LEAL, Mônia Clarissa Hennig. Os direitos fundamentais nas modernas Constituições: análise comparativa entre as Constituições Alemã, Norte-Americana e Brasileira. Revista de Direito, Santa Cruz do Sul, n. 28, p. 123-142, jul./dez. 2007.

CORTE INTERAMERICANA DE DIREITOS HUMANOS. Caso Ximenes Lopes versus Brasil: sentença de 04 de julho de 2006 (mérito, reparações e custas). São José da Costa Rica, 2006. Disponível em: <http://www.corteidh.or.cr>. Acesso em: 10 jan. 2015.

GAVARA DE CARA, Juan Carlos. La dimensón objetiva de los derechos sociales. Barcelona: Libreria Bosch, 2010.

GRINOVER, Ada Pellegrini. O controle jurisdicional de políticas públicas. 2. ed. Rio de Janeiro: Forense, 2013.

LEAL, Mônica Clarissa Hennig. Jurisdição Constitucional aberta: reflexões sobre a legitimidade e os limites da jurisdição na ordem democrática: uma abordagem a partir das teorias constitucionais alemã e norte-americana. Rio de Janeiro: Lumen Juris, 2007.

LEAL, Rogério Gesta. Perspectivas hermenêuticas dos direitos humanos e fundamentais no Brasil. Porto Alegre: Livraria do Advogado, 2000. 
MENDES, Gilmar Ferreira Mendes. Direitos Fundamentais e controle de constitucionalidade: estudos de direito constitucional. 2. ed. São Paulo: Instituo Brasileiro de Direito Constitucional, 1999.

MENDES, Gilmar Ferreira Mendes. Os Direitos Fundamentais e seus múltiplos significados na ordem constitucional. Revista de Direito do Estado (REDE), Salvador: Instituto Brasileiro de Direito Público, n. 23, jul./set. 2010. Disponível em: <http://www.direitodoestado.com/revista/REDE-23-JULHO-2010-GILMAR-MENDES.pdf>. Acesso em: 15 set. 2013.

NOVAIS, Jorge Reis. As restrições aos direitos fundamentais não expressamente autorizadas pela Constituição. Coimbra: Coimbra Editora, 2003.

PEREIRA, Jane Reis Gonçalves. Apontamentos sobre a aplicação das normas de direito fundamental nas relações jurídicas entre particulares. In: BARROSO, Luís Roberto. A nova interpretação constitucional: ponderação, direitos fundamentais e relações privadas. 2. ed. Rio de Janeiro: Renovar, 2003. v. 2. p. 119-191.

PEREZ LUÑO, Antonio E. Los Derechos Fundamentales. Madrid: Editorial Tecnos, 2005.

SARLET, Ingo Wolfgang. A Eficácia dos Direitos Fundamentais: uma teoria geral dos direitos fundamentais na perspectiva constitucional. Porto Alegre: Livraria do Advogado, 2010.

SARMENTO, Daniel. Direitos fundamentais e relações privadas. Rio de Janeiro: Lumen Júris, 2004.

SILVA, José Afonso da. Curso de Direito Constitucional Positivo. 35. ed. São Paulo: Malheiros, 2011.

Data da submissão: 20 de fevereiro de 2015 Avaliado em: 15 de abril de 2015 (AVALIADOR A) Avaliado em: 28 de março de 2015 (AVALIADOR B) Aceito em: 15 de abril de 2018 